\title{
SOBRE OLHARES E PRÁTICAS PSICOLÓGICAS NA ASSISTÊNCIA SOCIAL ${ }^{1}$
}

\author{
Gilead Marchezi Tavares ${ }^{2}$ \\ Universidade Federal do Espírito Santo, Vitória-ES, Brasil
}

\begin{abstract}
RESUMO. Em face da crescente entrada do psicólogo nos serviços de assistência social, este artigo visa analisar as práticas psicológicas no campo da infância e da juventude, buscando trazer à luz a complexidade e a historicidade de concepções correntes desse saber-fazer. O artigo constitui-se de estudo teórico que discute a atuação profissional do psicólogo, considerando os olhares e as práticas como constituídas na realidade e criadoras dessa realidade. Utilizando-se da biologia do conhecimento e da análise institucional francesa, reflete sobre as concepções de ser social, instituição, política e subjetividade. Considerando as formas de olhar como constituídas nas interações sociais e condicionadas aos contextos sociais e históricos, aponta para a reflexão sobre as práticas cotidianas a partir da problematização dos olhares sobre o mundo, e indagando sobre a inadequação das práticas psicológicas na assistência social, reporta-se ao campo das visibilidades nos serviços sociais e à diminuta aptidão da Psicologia para manejá-lo, em função de sua própria história clínica. Desse modo, conclui pontuando a análise das implicações e a intervenção nas instituições como tarefa ética do psicólogo.
\end{abstract}

Palavras-chave: Psicologia; subjetividade; ética.

\section{ABOUT SIGHTS AND PSYCHOLOGICAL PRACTICES IN SOCIAL ASSISTANCE}

\begin{abstract}
In view of the increasing entry of the psychologist in the social assistance services, this article aims at analyzing the psychological practices in the field of childhood and youth, highlighting the complexity and the historicity of current conceptions of this know-how. This theoretical study discusses the professional action of the psychologist, considering the sights and practices as both established in the reality and the creators of the reality. Using the biology of knowledge and French institutional analysis this paper reflects on the conceptions of social, institution, politics and subjectivity. Taking into consideration the ways of seeing as constituted in the social interactions and conditioned to social and historical contexts, it points towards the reflection about daily practices from the problematization of sights on the world. Inquiring about the inadequacy of the psychological practices in social assistance, it reports to the field of visibilities in social services and the diminished aptitude of Psychology in maneuvering it, related to its own clinical history. Therefore, it concludes assigning the analysis of implications and intervention in institutions as an ethical task of psychologist.
\end{abstract}

Keywords: Psychology; subjectivity; ethics.

\section{ACERCA DE MIRADAS Y PRÁCTICAS PSICOLÓGICAS EN ASISTENCIA SOCIAL}

RESUMEN. En vista de la creciente entrada de la psicología en los servicios de asistencia social, este artículo pretende analizar las prácticas psicológicas en el campo de la niñez y la juventud, tratando de sacar a la luz de la complejidad y la historicidad de los conceptos actuales de este know-how. Este estudio teórico que analiza el acción profesional del psicólogo, teniendo en cuenta las miradas y las prácticas establecidas en y la creación de realidad. Utilizando la biología del conocimiento y del análisis institucional francesa reflexiona sobre los conceptos del ser social, institución social, política y subjetividad. Teniendo en cuenta las formas de mirar cómo constituyen en las interacciones sociales y condicionadas a los contextos sociales e históricos, este artículo apunta a la reflexión sobre las prácticas diarias por la problematización de las perspectivas sobre el mundo. Preguntando sobre la inadecuación de las prácticas psicológicas de la asistencia social, se

1 Apoio Financeiro: à Fundação de Amparo à Pesquisa e Inovação do Espírito Santo (FAPES), pela bolsa de Pesquisador Capixaba

2 Endereço para correspondência: Rua Taciano Abaurre, 60, Ed. Oggi, ap. 1504, Enseada do Suá, CEP 29.050-470 Vitória-ES, Brasil. E-mail: gileadmt.2014@gmail.com. 
refiere al ámbito de los servicios sociales y la diminuta aptitud de Psicología a manejarlo, según su propio historial médico. Por lo tanto, señala el análisis de implicaciones y la intervención en las instituciones como tarea ética de psicólogos.

Palabras-clave: Psicología; subjetividad; etica.

Em que mundo nós vivemos?! Esta é a expressão do horror dramático que nos toma cotidianamente quando assistimos aos noticiários, que não cessam de nos apresentar fatos sanguinários, terríveis, que dizem respeito a ações de humanos contra humanos. Podemos afirmar que as cenas que mais causam comoção geral neste início de século são as que tratam de negligência, maus-tratos, abusos (e tudo o mais) contra crianças, ao mesmo tempo em que infrações cometidas por crianças e adolescentes causam ódio e ânsia de punição. Ao lado desse estilo dramático estamos nós, os profissionais da psicologia, atuando nas políticas públicas de assistência social, com a função percebida por muitos como a de "enxugar gelo" e "apagar incêndio".

Os serviços do atual Sistema Único de Assistência Social têm absorvido uma parte dos psicólogos recém-formados que se perguntam sobre sua função nos serviços. Tal indagação parece ecoar imediatamente nos cursos de graduação, soando quase como uma acusação de que os cursos não estão preparados para formar o egresso com um perfil para a atuação na assistência social. A partir de tal problemática, pretendemos, neste artigo, analisar as práticas psicológicas, especialmente no que se refere à atuação no campo da infância e da juventude, buscando trazer à luz a complexidade e a historicidade de concepções correntes de nosso saber-fazer.

\section{PENSANDO AS ATUAIS CONQUISTAS E MUDANÇAS NA ASSISTÊNCIA SOCIAL}

Até a Constituição Federal de 1988 as políticas de assistência social que compõem grande parte da assistência à criança e ao adolescente no Brasil eram concebidas como ações isoladas de doação e caridade; mas a partir de então passaram a vigorar como políticas públicas, figurando no campo dos direitos e da responsabilização estatal.

É preciso pensar na história dos movimentos sociais e no campo das lutas sociais para não nos equivocarmos no que diz respeito à conquista dos direitos. As diversas vozes e as forças em disputa estão presentes na efetivação dos direitos. Talvez já esteja claro para alguns que a promulgação de uma lei não apaga todos os processos em curso na história. Por exemplo, - Estatuto da Criança e do Adolescente não baniu concepções e práticas relativas ao menor e à menoridade, e o Sistema Nacional de Atendimento Socioeducativo não tem impedido certo clamor social por redução da idade penal. Talvez a questão seja exatamente a captura dos movimentos sociais pelos processos de judicialização da vida em que se acredita que a lei tudo resolve, que a punição é o melhor caminho e que a história tem um fim.

A Lei de Organização da Assistência Social (LOAS, Lei Federal $n^{\circ}$ 8742/93) regulamentou os artigos 203 e 204 da Constituição Federal de 1988, inserindo a assistência social na Política de Seguridade Social não contributiva. A assistência social, juntamente com a saúde e a previdência social, tem como proposta a promoção do bem-estar social do brasileiro. Dessa forma, a assistência social é um dever do Estado e um direito de toda pessoa, como membro da sociedade, quando dela necessitar. Entre as Diretrizes da LOAS aparece a participação da população, por meio de organizações representativas, na formulação das políticas e no controle das ações em todos os níveis através da criação dos Conselhos de Assistência Social e a primazia do Estado na condução da política de assistência social. Após ampla discussão em encontros, seminários, reuniões, oficinas e palestras em todo território brasileiro, o Conselho Nacional de Assistência Social aprovou, em 2004, a Política Nacional de Assistência Social (PNAS).

Na PNAS, a assistência social define como seu público-alvo os cidadãos e os grupos que se encontrem em situação de vulnerabilidade e de risco. Segundo as Normas Operacionais Básicas do Sistema Único de Assistência Social (NOBSUAS, Brasil, 2005), a vulnerabilidade social é decorrente da pobreza, da privação (entendida como ausência de renda, precário ou nulo acesso aos serviços públicos, dentre outros) e/ou fragilização de vínculos afetivos, sejam eles relacionais ou de pertencimento social, sendo considerada, para compor a Taxa de 
Vulnerabilidade de determinado território, a combinação de diversas características da população, como infraestrutura de moradia, renda per capita, anos de escolaridade, presença de crianças, idosos e/ou deficientes. Pode-se afirmar que a vulnerabilidade diz respeito mais à condição concreta (nível socioeconômico, classificação racial, diferenciação de gênero, etc.) dos sujeitos em relação ao seu contexto de vida, do que a situações provisórias. Os riscos, por sua vez, dizem respeito à dimensão de precarização situacional, que pode ser decorrente das condições de vida dos sujeitos ou não:

A proteção social de assistência social se ocupa das vitimizações, fragilidades, contingências, vulnerabilidade e riscos que o cidadão, a cidadã e suas famílias enfrentam na trajetória de seu ciclo de vida por decorrência de imposições sociais, econômicas, políticas e de ofensas à dignidade humana (Brasil, 2005, p. 15).

Segundo Costa (1990), a categorização das pessoas como em situação de risco social aparece na década de 90 para circunscrever aqueles em "condição de subcidadãos ou cidadãos de segunda classe" (p. 72) a quem se destina a ação assistencial do Estado. Interessante notar que o Estado, ao não chegar para todos pelas políticas sociais básicas, produz uma categoria de pessoas que rotula de situações de risco. Para estas, inventa toda uma estratégia governamental, com políticas, serviços e equipamentos para atendimento.

No Brasil do século XXI, seguindo a nova ordem do capitalismo mundial, vemos despontar uma maciça produção de insegurança, aliada ao crescimento do desemprego e à exclusão social ligada à pobreza. Os pobres e os negros são vistos como os agentes da insegurança, aqueles que devem ser monitorados. A infância e a juventude pobres estão sendo controlados, pois poderão formar as "classes perigosas" num futuro próximo (Coimbra \& Nascimento, 2005). O que colocamos aqui em questão é como (a partir de quais técnicas, quais práticas e quais olhares) as instituições de controle estão produzindo crianças e adolescentes em situação de risco social (Hüning \& Guareschi, 2009).

A Política Nacional de Assistência Social tem como funções a proteção social (básica e especial), a defesa dos direitos socioassistenciais e a vigilância social (Brasil, 2004). Esta última, em especial, consiste em desenvolver meios de gestão para conhecer a presença das formas de vulnerabilidade social e de riscos presentes na população e no território para se reordenarem as políticas sociais, ou seja, a produção de taxas de vulnerabilidade e indicadores de risco.

Não é preciso lembrar que a PNAS constituise como resultado de trabalho democrático e descentralizado e que não se coloca em questão sua importância no campo das lutas sociais. De todo modo, isto não deve nos impedir de pensar sobre o que ela tem produzido, uma vez que a história social do Brasil não terminará nela. Assim, ao evidenciarmos a ideia de risco social como demarcadora das crianças pobres (Tavares et al., 2011; Tavares, Guidoni \& Capelini, 2013), não podemos deixar de nos perguntar a que as políticas de assistência social têm servido.

Nesse sentido, Foucault (2008) nos ajuda a abrir o campo de visão ao falar de biopolítica. $\mathrm{O}$ autor a compreende como estratégia do biopoder que possibilita o investimento das forças na população como um todo no homemespécie, a partir da tecnologia das forças estatais, a polícia (Foucault, 2008), que dá visibilidade à população como um conjunto de seres vivos e coexistentes que apresentam características biológicas e patológicas específicas. Esclarece o autor:

\begin{abstract}
E, para administrar essa população, é necessária, entre outras coisas, uma política de saúde capaz de diminuir a mortalidade infantil, de prevenir as epidemias e de fazer baixar a taxa de endemia, de intervir nas condições de vida, para modificá-las e impor-lhes normas (quer se trate de alimentação, de hábitat ou de urbanização das cidades) e proporcionar equipamentos médicos suficientes. O desenvolvimento a partir da segunda metade do século XVIII do que foi chamado Medezinische Polizei, hygiene publique, social medicine, deve ser inscrito no marco geral de uma "biopolítica".... (Foucault, 2008, p. 494).
\end{abstract}

Foucault (2002), ao falar de biopoder, descreve técnicas de regulamentação da vida, diferenciando a população que deve ser protegida daquela que deverá ser combatida em nome da defesa da sociedade. A partir da ascensão dos mecanismos de controle da vida 
das populações, a concordância com a exclusão (ou eliminação) de determinada categoria de pessoas baseia-se na premissa de que tais sujeitos oferecem perigo às vidas eleitas como superiores.

Biopoder seria um poder característico dos modos de funcionamento do sistema capitalista, exercido através de uma tecnologia de dupla face: a disciplinar, que se dirige ao homemcorpo, e a biopolítica, que mobiliza a gestão da vida dirigindo-se à população como um todo, ao homem-espécie. O biopoder operacionaliza uma incidência que se caracteriza por uma organização rizomática e por uma ação disseminada nos mais ínfimos detalhes da vida, revestindo-a de ponta a ponta e regulamentando um direito que consiste "em fazer viver e em deixar morrer" (Foucault, 2002, p. 294).

Nesse novo diagrama de forças torna-se fundamental, então, conduzir a população e os indivíduos de modo a gerir a vida, o que se dá tendo-se como suporte uma rede de instituições que tem como objetivo vigiar e corrigir. A vigilância configurava-se inicialmente como técnica disciplinar operada pela polícia, enquanto a correção cabia às instituições psicológicas, psiquiátricas, criminológicas, médicas e pedagógicas. Com o refinamento e a expansão do biopoder, a partir do século XIX, podemos pensar que a função da polícia, como prática judiciária, é investida pelas ciências médicas e humanas que produzem uma torção no poder codificado de punir, relativo ao Direito, em um poder disciplinar de vigiar, utilizado agora pelas práticas profissionais do campo da saúde e da assistência social (Arantes, 2008).

Nesse sentido, a vigilância passa a ter um papel crucial no desenvolvimento de um conhecimento acerca dos territórios habitados pelos grupos humanos que passarão a ser esquadrinhados e monitorados. Trata-se de uma regulamentação da vida em nome de uma proteção/prevenção dos indivíduos e em defesa da sociedade. A proteção/prevenção deverá ser realizada a partir do controle e da gestão dos riscos. Acontece que é também nos Estados Nacionais - que agora são governamentalizados e investem na intensificação da vida -, que grande parcela da população será paradoxalmente exposta ao "assassínio indireto: o fato de expor à morte, de multiplicar para alguns o risco de morte ou, pura e simplesmente, a morte política, a expulsão, a rejeição, etc." (Foucault, 2002, p. 306). Isso se dá pela imputação de uma defasagem entre os grupos no interior da população a partir do mapeamento das normalidades diferenciais (Foucault, 2008).

Esse estudo de Foucault não deve ser negligenciado, pois se sabe que a epidemiologia atravessa todas as políticas, gerando os indicadores imprescindíveis para a atuação do Estado, entre eles os indicadores ou taxas de risco social e pessoal. Além disso, parte do trabalho nos serviços de assistência social refere-se ao encaminhamento a conselhos tutelares e sistemas de justiça, à fiscalização do cumprimento de medidas judiciais e a certa regulamentação dos modos de vida.

\section{OLHARES E PRÁTICAS PSICOLÓGICAS}

É concepção corrente na Psicologia, ainda que não consensual, que o homem é um ser social, ou seja, que somos constituídos no universo social. Do que se trata quando falamos em universo social? Talvez possamos apostar que se trata, em última análise, das redes de relações interpessoais que travam os seres humanos uns com os outros ao longo da história e de suas vidas. Está claro que é algo bastante complexo.

Por isso acreditamos na importância de trazermos dois biólogos chilenos que, perseguindo a transdisciplinaridade, na segunda metade do século $X X$ problematizaram a ideia de ser vivo corrente, colocando em análise a constituição do ser humano. Humberto Maturana e Francisco Varela (2002), ao afirmarem que o ser vivo é um sistema de conhecimento autopoiético, vão além ao demonstrar que viver é conhecer e conhecer é fazer. $O$ fazer autopoiético diz de nosso perceber/conhecer sobre o mundo. É autopoiético porque somos um sistema que se autoproduz a todo o tempo no nosso fazer, e é assim que os citados biólogos constroem a tese do criacionismo ateu: como o mundo não está fora do sistema autopoiético, ele é produzido ao mesmo tempo em que o sistema se produz. Este fazer é inerente ao processo de perceber o mundo, porém percebemos que 0 mundo não está fora. Perceber é conhecer, e desse modo, conhecer, nos termos da ontologia do presente dos autores, é exatamente inventar o mundo. Concluindo, somos aquilo que fazemos, somos aquilo que vemos, assim como fazemos o mundo no qual vivemos. 
Acontece que um fazer não se encerra em si mesmo, porque ele se dá sempre enredado num conjunto de fazeres simultâneos, movidos por perturbações de ordens difusas. Somos afetados por aquilo que fazemos a todo o tempo. O que fazemos produz reverberações, e não produtos diretos. Chamaremos as reverberações de efeitos, que se diferenciam de produtos. $O$ produto fala de fabricação em série, previsível, regular. Não é disso que trata o conhecer autopoiético.

As ideias de Maturana e Varela (2002) nos convidam a pensar sobre nossos olhares como possibilidade de efetuar um devir-consciente daquilo que nos habita de forma opaca (Depraz, Varela \& Vermesch, 2006). O olhar não é algo natural, pois o mundo não se encontra lá fora estático e pronto para ser enxergado. Olhar diz de interações/afetações. É por mediação que vemos o mundo. Explica Zanella (2006, p. 143):

\begin{abstract}
O primeiro aspecto a destacar a respeito do olhar é a condição social e histórica que se, por um lado, depende do olho físico, por outro, o transcende na medida em que é produzido nas/pelas relações sociais em que pessoas concretas se inserem e das quais ativamente participam. ... Nossos olhares, portanto, estão sendo forjados/educados desde o momento em que nascemos e dificilmente nos damos conta das estereotipias, dos enrijecimentos, dos vieses de classe social, de etnia, de gênero, de condição cultural que caracterizam as leituras que fazemos da realidade (Zanella, 2006, p. 143).
\end{abstract}

Parece-nos pertinente indagar sobre os olhares da Psicologia, uma vez que o grande mote da profissão de psicólogo é a escuta. A escuta, vinculada à fala do paciente, aparece como o instrumental que possibilita a percepção das respostas necessárias a cada situação. $O$ que há no campo da assistência que apresenta uma inadequação de tal prática psicológica? Talvez o campo das visibilidades e nossa pouca aptidão para manejá-lo. Diríamos que a Psicologia precisa saber dos seus próprios olhares, da nossa visão de mundo e de homem.

$\mathrm{O}$ que queremos com o nosso olhar punitivo e moralizante diante de modos de vida diversos? $\mathrm{O}$ que queremos com o nosso olhar inquisidor no campo jurídico? $\mathrm{O}$ que queremos quando abordamos as questões presentes nas nossas relações a partir do olhar sobre um mundo dividido e em movimento de pêndulo entre vítimas e agressores? Que mundo ajudamos a construir quando olhamos a criança pobre como sendo de risco - leia-se possível criminoso -, lembrando que o possível é do campo do real? Que mundo ajudamos a construir quando olhamos o jovem pobre, o jovem negro, como problema social - leia-se perigoso? Nosso olhar constitui mundos, realidades. Há sempre uma política no olhar. Talvez seja necessário "olhar com os olhos dentro" (menção ao título do artigo de Sordi, De-Nardi \& Farias, 2008), pois talvez haja um Estado violento em nós, e quem sabe possamos ver, além e aquém, o movimento da vida.

\section{POLÍTICAS E PRÁTICAS PSICOLÓGICAS}

Acreditamos que cabe ao profissional
psicólogo intervir nas instituições,
desmanchando territórios constituídos e convocando à criação de espaços de passagem de um território a outro. Cabe ao psicólogo analisar as políticas institucionais e produzir novas políticas. Com o aporte do movimento institucionalista francês, chamamos de instituição o processo de produção constante de modos de legitimação das práticas sociais que dizem respeito aos estabelecimentos $e$ às organizações sociais de modo geral (Baremblitt, 2002). Nesse sentido, estamos inevitavelmente implicados nas instituições, uma vez que as experiências que nos compõem são guiadas pelas práticas sociais.

Por política entendemos a direção dos vetores envolvidos nos processos de produção de subjetividade. Tal direção se manifesta nas ações/relações dos sujeitos caracterizadas como exercício de poder. Indagar a política é problematizar a direção do curso da vida, é investigar se as forças presentes no visível e no invisível das relações caminham para o aumento da potência da vida ou para o seu aniquilamento. As políticas produzem modos de vida e exatamente por isso se dão sempre como processos de subjetivação. Trata-se, como escreveram Guattari e Rolnik (2005), de colocar a micropolítica em todas as partes.

Com se compreende que a política é a direção do poder, é a tendência imposta pelo poder, e que o poder é relação de forças, "é ação sobre a ação, sobre as ações eventuais, ou atuais, futuras ou presentes" (Deleuze, 1991, p. 
78), pode-se utilizar a ontologia da realidade de Maturana \& Varela (2002) na composição ação/relação. Toda relação deriva de uma ação, não há relação sem movimento, processo, dinâmica. Toda ação emana de relações, portanto estamos falando de um sistema recursivo de autoprodução do vivo.

Como indagamos sobre a direção das práticas psicológicas na assistência social, precisamos falar ainda de atuação. Gostaríamos de apresentar a atuação profissional como corporificação do conhecimento, tomando emprestado o conhecimento de Varela (2003). O autor utiliza o termo inglês enact, que traduzimos aqui como atuação, para dar lugar, nas ciências cognitivas, à ideia de cognição corporificada, encarnada, distanciando-se assim da ideia de cognição como processo mental. A atuação diz de ações que se inscrevem no corpo, emergentes de experiências concretas vividas. $O$ conceito de atuação traz para nosso campo de estudos pressupostos do pensamento pragmático, compreendendo que o conhecimento parte do colocar-se em ação, envolvendo-se nesse processo o corpo inteiro.

Dessa forma, nossas histórias, nossa linguagem e todo o contexto vivido constituem-se como material indispensável para a produção de uma cognição inventiva que se registra no corpo. Nesse sentido, não se pode pensar apenas a prática profissional, como se ela pudesse estar descolada, desvinculada de nossa vida, de quem somos nós, do que conhecemos. A atuação é um domínio cognitivo, ou seja, é domínio experiencial dependente da posição, da direção e da história de cada um de nós que emerge sempre das interações sociais. Falar de atuação é lembrar o que nos compõe, é nos perguntar qual é o nosso compromisso ou o nosso comprometimento, com o quê e com quem, é colocar em análise a nossa implicação nas instituições, no mundo inventado.

Somos seres sociais, somos intensidades relacionais afetivas, ou seja, capazes de afetar, de produzir modos finitos de olhar, de fazer. Partindo de tal entendimento, apontamos para os modos de ser e estar não como essência de um sujeito, pois consideramos que sempre estamos nos fazendo nas relações cotidianas. Percebamos que colocar em análise este fazer (nossas práticas - aquilo que dizemos, pensamos ou fazemos) é o eixo político e ético para a compreensão dos processos de subjetivação que engendram subjetividades diversas.

Desse modo, a subjetividade é aqui entendida como formas de ser, de estar e sentir que não se encontram dentro do sujeito como uma essência, por exemplo, ou como verdade interior da pessoa, mas que compõem os sujeitos por atravessamentos. As subjetividades configuram-se como práticas repetidas, automáticas, que surgem instantaneamente nos corpos em função de sua repetição. Como práticas, elas compõem modos de vida, mas não se constituem como propriedade ou atributo de um sujeito. As práticas atualizam-se nos sujeitos, mas não possuem donos, não têm lugar fixo, pressupondo, assim, processos permanentes de vir a ser. É por essa via que compreendemos que a subjetividade criminosa não está dentro de ninguém. $O$ sujeito pode cometer um ato criminoso, mas isso não significa que ele seja criminoso, já que não há substância finalizada, terminada, acabada.

Tomando como referência novamente os trabalhos de Foucault (2010a), percebemos que a formação das sociedades estatais ocorreu junto e por meio de grandes transformações nas práticas sociais, entre elas a impregnação do olhar pelas regularidades, pelas formas. O olhar, sendo treinado minuciosa e diariamente para buscar a estabilidade, perdeu de vista o movimento imanente ao tempo que produz tudo o que há por operação contínua de diferenciação. Se só vemos a regularidade e a estabilidade é porque a cada dia fazemos o mesmo de nós mesmos, daqueles com os quais lidamos e do mundo.

Seguindo a análise de Foucault (2010b), pensamos o mundo contemporâneo não pela sua forma, mas pelas suas intensidades, pelos seus fluxos, pelos seus processos. Foi fazendo isso que ele inventou um modo diferente de olhar o tecido social. Ao colocar em análise as relações de força, ou seja, de poder da sociedade moderna, ele traçou o que chamou de diagrama: dimensão informe das relações de poder coextensivas a todo o campo social. Para fazer isto ele tomou como ferramentas conceitos que operam na realidade como pás escavadeiras ou chaves de fenda que abrem fendas, brechas na realidade para a produção de outros e novos mundos. É assim que o conceito de dispositivo nos auxilia na análise e na decomposição de estruturas concretas ou agenciamentos diversos que fabricam discursos 
tidos como verdadeiros e formas definidas de viver (modelos/padrões para os modos de vida).

Foi assim que Foucault (1989) tornou visível a instituição prisão como dispositivo que produz o delinquente e toda uma ciência sobre a delinquência (a criminologia). A prisão, aqui pensada como instituição, não é o lugar físico, o estabelecimento prisional, mas sim, o conjunto de concepções e práticas que dão luz à prisão e que são compreendidas no campo social como naturais, universais e, por isso, verdadeiras.

$\mathrm{O}$ que temos produzido com as medidas socioeducativas? A identidade de adolescente em conflito com a lei e um grande discurso sobre risco social? (Siqueira, 2011). É urgente que nos perguntemos - nos cursos de graduação, na atuação profissional, nas pesquisas, em todos os lugares: como vamos lidar com isso? Vamos continuar a falar que o depoimento sem danos é a expressão do direito da criança de ser ouvida quando a criança pobre muitas vezes não é vista e na maioria das vezes não é vista como gente? Vamos dizer que há crianças agressoras na escola quando na própria escola a criança não é vista como sujeito de direitos: direito de ser acolhida em suas diferenças, direito de ver sua família como locus de eticidades diversas e diferentes das camadas médias e altas? Vamos dizer que o jovem que se confronta com o poder e por isso está incluído perversamente em dispositivo concreto de controle, é perigoso, é psicopata, é portador de um mal, quando não enxergamos sua potência em resistir à tentativa esmagadora de torná-lo estorvo, subalterno, inferior?

Se isto acontece, não é porque se é ou se tem uma forma regular, estável, pronta para atuar no mundo, mas porque está se fazendo a todo o tempo o mesmo. O que queremos dizer com isto é que, quando vemos o jovem como adolescente em conflito com a lei, favorecemos um olhar sobre o sujeito que existe a partir de uma infração, e infração aqui tem conotação de crime, relativo a alguém que vemos como criminoso ou monstruoso. O crime está sendo atualizado, mesmo que de diferentes modos, e o menino vai se fazendo em relação aos profissionais que o atendem como aquele que cometeu um ato infracional/criminoso. Ele passa a ser visível quando se confronta com o poder: falem mal, mas falem de mim... Enxerguem-me, quero existir, mesmo que para isso deva ser visto como criminoso!
Estando todas as relações interligadas por agenciamentos difusos, não há na sociedade aquele que esteja excluído, ou não podemos dizer que haja o excluído. Todas as formas são definidas nas e a partir das relações. Se há o delinquente é porque este está incluído na engrenagem que produz formas normais e perigosas de existir. Há assim formas perversas de inclusão.

\section{A PRÁTICA PSICOLÓGICA COMO ABERTURA À EXPERIÊNCIA}

Propomo-nos a ver a exclusão de modo diferente, como aquilo que rompe com práticas repetitivas ou o acontecimento que abre o campo de ação para novas possibilidades, novas práticas, novos mundos. Tal abertura do campo do sensível se faz a todo o momento, mas parece ter se tornado invisível em função dos automatismos e dos procedimentos técnicos investidos pelas forças do Estado. $O$ bom combate a tais forças de captura requer um exercício ético dentro de um paradigma que chamamos de ético-estético-político.

\begin{abstract}
Ético, no que se refere ao desejo de diferir e acolher a diferenciação constante; estético, no que se refere a tomar a existência e as práticas nas quais se produzem como matéria de criação e outramento; político, porque requer a problematização e a desnaturalização constante dos intoleráveis que atravessam a nossa existência e nos servem como indicadores de nossas ações em relação a nós mesmos e aos outros (Neves, 2004, p. 12).
\end{abstract}

O exercício ético, então, diz respeito a esforçarmo-nos por fazer de nossa vida, a cada nova tentativa, uma obra de arte, no sentido de acolhimento da diferença a partir de vetores que indicam a expressão da vida, a experiência. Configura-se como um observar atento, mas sem arrogância, dos vetores presentes nas práticas: se apontam para a reprodução da engrenagem que põe em funcionamento subjetividades criminosas - por meio da disseminação do medo, da desconfiança, da violência, ou se apontam, ao contrário, para a formação de uma zona de confiança, na abertura para um plano imanente de construção do comum, na potência de ação humana que 
embarca no movimento de duração da vida. Afirmamos sem arrogância porque se trata sempre de um olhar para dentro na tentativa de forjar uma nova entrada para a experiência.

Scheinvar e Cordeiro (2007), em trabalho sobre juventude em risco social, formulam uma crítica à utilização da noção de risco para a infância e juventude pobres e afirmam:

O que é visto como rebeldia nos jovens também pode ser lido como potência. Como resistência a políticas padronizadas que em nada modificam o lugar em que se cristaliza à juventude, seja ela pobre ou não. O olhar que os petrifica em uma única forma é desviado com seus atos, suas inquietações, sua contestação - a partir dos recursos que Ihes são possíveis -, expressando tanto a recusa às respostas públicas restritas a discursos morais e punitivos como a potência com a qual afirmam o seu direito à vida (Scheinvar \& Cordeiro, 2007, p. 11).

Desse modo, o convite que é feito a todo psicólogo diz de um preocupar-se consigo mesmo, de um olhar mais atento e aberto, de escutar mais do que vem escutando, pois:

Não se habita o mundo da mesma forma quando se escuta o lamento da terra seca, o leito vazio do rio, a mão suplicante que se estende em busca de alimento e abrigo, ou o olhar de um qualquer vivente em busca de simpatia, amizade ou compaixão. Não se habita o mundo da mesma forma quando se escutam vozes misteriosas ou do além, quando se tem medo do escuro $\mathrm{e}$ também do claro, quando não se sabe se é dia ou se é noite, quando não mais importa se homem ou se mulher, se árvore ou um riacho, ou se nossas conversações "fazem parte da guerra ou já da paz" (Deleuze, 1992, citado por Arantes, 2012, p. 93).

A psicologia já fez 50 anos, já revisou a sua história e o seu comprometimento com as elites (Bock, 2009), já afirmou o seu compromisso com a realidade social do país e já delimitou o seu foco de trabalho como sendo a promoção de saúde. Aqui desembarcamos nós. Quanto à pergunta sobre qual é o nosso compromisso, com o quê e com quem, diríamos que só pode ser com a vida. Diríamos, ainda, que a análise de implicação é um dos instrumentos fundamentais para quem tem a urgência guerreira de lutar pela afirmação da vida.

\section{REFERÊNCIAS}

Arantes, E. M. M. (2008). Mediante quais práticas a Psicologia e o Direito pretendem discutir a relação? Anotações sobre o mal-estar. In C. M. B. Coimbra; L. S. M. Ayres \& M. L. Nascimento (Orgs.). Pivetes: Encontros entre a Psicologia e o Judiciário (pp. 131-148). Curitiba: Juruá.

Arantes, E. M. M. (2012). Escutar. In T. M. G. Fonseca; M. L. Nascimento \& C. Maraschin (Orgs.). Pesquisar na diferença: um abecedário (pp. 93-96). Porto Alegre: Sulina.

Baremblitt, G. (2002). Compêndio de análise institucional e outras correntes. Belo Horizonte: Instituto Félix Guattari.

Bock, A. (Org.) (2009). Psicologia e compromisso social. São Paulo: Cortez.

Brasil. (2004). Ministério do Desenvolvimento Social e Combate à Fome. Secretaria Nacional de Assistência Social. Política Nacional de Assistência Social - PNAS. Brasília.

Brasil. (2005). Ministério do Desenvolvimento Social e Combate à Fome. Secretaria Nacional de Assistência Social. Norma Operacional Básica - NOB/SUAS. Brasília.

Costa, A. C. G. (1990). Infância, juventude e política social no Brasil. In A. C. G Costa (Org.). Brasil e criança urgente: a lei 8.069/90 (pp. 69-97). São Paulo: Columbus.

Coimbra, C. M. B. \& Nascimento, M. L. (2005). Ser jovem, ser pobre é ser perigoso? JOVENes - Revista de Estudios sobre Juventud, 9(22), 338-355.

Deleuze, G. (1991). Foucault. São Paulo: Brasiliense.

Depraz, N; Varela, F. J. \& Vermesch, P. (2006). A redução à prova da experiência. Arquivos Brasileiros de Psicologia, 58(1), 75-86.

Foucault, M. (1989). Vigiar e Punir: história da violência nas prisões. Petrópolis: Vozes.

Foucault, M. (2002). Em defesa da sociedade. São Paulo: Martins Fontes.

Foucault, M. (2008). Segurança, Território, População. São Paulo: Martins Fontes.

Foucault, M. (2010a). Ditos \& Escritos VI, Repensar a política. Rio de Janeiro: Forense Universitária.

Foucault, M. (2010b). O governo de si e dos outros. São Paulo: Martins Fontes.

Guattari, F. \& Rolnik, S. (2005). Micropolítica: cartografias do desejo. Petrópolis: Vozes.

Hüning, S. M. \& Guareschi, N. M. F. (2009). A cidade precisa dormir em paz: relações entre educação, psicologia e risco social. Cadernos de Educação (UFPel), 32, 41-62.

Lei Federal no 8.742 - LOAS, de 7 de dezembro de 1993. (1993, 7 de dezembro). Dispõe sobre a organicidade da Assistência Social no território brasileiro. Brasília, DF: Presidência da Repúblia: Casa Civil. Subchefia para Assuntos Jurídicos.

Maturana, H. R. \& Varela, F. J. (2002). A árvore do conhecimento: as bases biológicas da compreensão humana. São Paulo: Palas Athena. 
Neves, C. E. A. B. (2004). Modos de interferir no contemporâneo: um olhar micropolítico. Arquivos Brasileiros de Psicologia, 56(1), 2-19.

Scheinvar, E. \& Cordeiro, D. (2007). Juventude em "risco social"? Dilemas e perspectivas por entre as pedras das políticas públicas dirigidas aos jovens. Informativo TécnicoCientífico Espaço, (27), 55-63.

Siqueira, L. A. R. (2011). Habitando sentidos no encontro com jovens "capturados" pelo sistema de justiça: um estudo sobre as trajetórias de vida de adolescentes em conflito com a lei atendidos pelo Programa LAC/PSC de Vitória (ES). Dissertação de Mestrado Não-Publicada, Programa de Pós-Graduação em Psicologia Institucional, Universidade Federal do Espírito Santo, Vitória.

Sordi, R.; De-Nardi, M. H \& Farias, B. (2008). Olhar com os olhos de dentro: uma experiência de aprendizagem da atenção. Arquivos Brasileiros de Psicologia, 60(1), 14-31.

Tavares, G. M.; Guidoni, J. P. \& Capelini, T. C. (2013). As práticas que compõem e educação integral em Vitória (ES): uma análise da relação infância/pobreza/risco. In L. R. Cruz; L. Rodrigues \& N. M. F. Guareschi (Orgs.). Interlocuções entre a psicologia e a política nacional de assistência social [recurso eletrônico] (pp. 43-58). Santa Cruz do Sul: EDUNISC.
Tavares, G. M.; Oliveira, F. T.; Bossatto, T.; Deus, F. B.; Coelho, D. C. \& Vilas-Boas, M. N. S. (2011). A produção de meninos de projeto e acontecimentos no percurso. Psicologia \& Sociedade; 23(1), 94-102.

Varela, F. (2003). O reencantamento do concreto. In: P. P. Pelbart \& R. Costa (Org.). Cadernos de Subjetividade: o reencantamento do concreto (pp. 71-86). São Paulo: Hucitec.

Zanella, A.V. (2006). Sobre olhos, olhares e seu processo de (re)produção. In L. H. C. Lenzi; S. Z. Ros; A. M. A Souza \& M. M. Gonçalves (Orgs.). Imagem: intervenção e pesquisa (pp. 139-150). Florianópolis: UFSC: NUP/CED/UFSC.

Recebido em 15/10/2013 Aceito em 12/09/2014

Gilead Marchezi Tavares: doutora em Psicologia, professora do Departamento de Psicologia e do Programa de PósGraduação em Psicologia Institucional da Universidade Federal do Espírito Santo. 